\title{
O PDDI-RMBH E AS POSSIBILIDADES DE UM DESENVOLVIMENTO ENDÓGENO DESENCADEADO PELA ECONOMIA POPULAR METROPOLITANA
}

\author{
Evandro Luis Alves* \\ Bruno Siqueira Fernandes* \\ Sibelle Cornélio Diniz ${ }^{* *}$ \\ * Universidade Federal de Minas Gerais, Escola de Arquitetura, Belo Horizonte, MG, Brasil. \\ ** Universidade Federal de Minas Gerais, Instituto de Geociências, Belo Horizonte, MG, Brasil. \\ *** Universidade Federal de Minas Gerais, Faculdade de Ciências Econômicas, Belo Horizonte, MG, Brasil.
}

\begin{abstract}
Resumo
Aprovado em 2011, o Plano Diretor de Desenvolvimento Integrado da Região Metropolitana de Belo Horizonte (PDDI-RMBH) é peça fundamental do processo continuado de planejamento metropolitano em Minas Gerais. Em sua referência à produção em pequena escala, chama atenção o fato de o Plano tomar a tese da economia popular solidária como pressuposto para o planejamento. Este artigo pretende explorar essa questão, uma década após a elaboração e a aprovação do documento, apontando os limites e as potencialidades de a economia popular se tornar base desencadeadora de uma trajetória de desenvolvimento endógeno na metrópole.

Palavras-chave

Planejamento metropolitano; PDDI-RMBH; Economia popular; Desenvolvimento endógeno; Minas Gerais.
\end{abstract}




\title{
PDDI-RMBH AND THE POSSIBILITIES OF AN ENDOGENOUS DEVELOPMENT LAUNCHED BY THE METROPOLITAN POPULAR ECONOMY
}

\author{
Evandro Luis Alves* \\ Bruno Siqueira Fernandes** \\ Sibelle Cornélio Diniz ${ }^{* *}$ \\ * Universidade Federal de Minas Gerais, Escola de Arquitetura, Belo Horizonte, MG, Brazil. \\ ** Universidade Federal de Minas Gerais, Instituto de Geociências, Belo Horizonte, MG, Brazil. \\ *** Universidade Federal de Minas Gerais, Faculdade de Ciências Econômicas, Belo Horizonte, MG, Brazil.
}

\begin{abstract}
The Integrated Development Master Plan of the Metropolitan Region of Belo Horizonte (PDDI-RMBH) was approved in 2011, and it is a fundamental part of the continuous process of metropolitan planning in Minas Gerais. In its reference to small-scale production, it is noteworthy that the Plan takes the thesis of the solidary popular economy as a presupposition for planning. This article intends to explore this issue, a decade after the document was drafted and approved, pointing out the limits and the potential of the popular economy to become the basis for an endogenous development in the metropolis.

Keywords

Metropolitan planning; PDDI-RMBH; Popular economy; Endogenous development; Minas Gerais.
\end{abstract}




\title{
O PDDI-RMBH E AS POSSIBILIDADES DE UM DESENVOLVIMENTO ENDÓGENO DESENCADEADO PELA ECONOMIA POPULAR METROPOLITANA
}

\author{
Evandro Luis Alves \\ Bruno Siqueira Fernandes \\ Sibelle Cornélio Diniz
}

\section{Introdução}

Aprovado em 2011, o Plano Diretor de Desenvolvimento Integrado da Região Metropolitana de Belo Horizonte (PDDI-RMBH), ou Plano Metropolitano, é peça fundamental do processo continuado de planejamento metropolitano no estado de Minas Gerais'. Um dos objetivos apresentados pelo Plano é a indução do desenvolvimento de uma "novíssima economia mineira”. Em especial na sua referência à produção em pequena escala, chama atenção o fato de o Plano tomar a tese da economia popular solidária como pressuposto para o planejamento. Nesse sentido, o PDDI-RMBH criou um precedente peculiar e ainda pouco explorado para a concepção de uma trajetória de desenvolvimento endógeno alinhada à ideia de de-

\footnotetext{
1. O PDDI-RMBH foi elaborado entre 2009 e 2010 sob a coordenação do Centro de Desenvolvimento de Planejamento Regional da Universidade Federal de Minas Gerais (Cedeplar/UFMG), envolvendo vários departamentos dessa universidade, além da Pontifícia Universidade Católica de Minas Gerais (PUC Minas) e da Universidade do Estado de Minas Gerais (UEMG), e contando com uma equipe de cerca de 180 professores, pesquisadores e estudantes. O Plano, cujo intuito era constituir-se em um instrumento central do planejamento metropolitano, foi demandado à UFMG em decorrência da criação de um arranjo institucional composto de um Conselho de Desenvolvimento Metropolitano, uma Assembleia Metropolitana e uma Agência de Desenvolvimento Metropolitano, articulados com o governo estadual (Leis Estaduais Complementares 88, 89 e 90/2006), além de um Fundo de Desenvolvimento Metropolitano. A elaboração do PDDI-RMBH foi resultado de um grande processo participativo, com três ciclos de oficinas nos municípios e dois seminários metropolitanos. Seu documento final estabelece diretrizes para a reestruturação territorial e propostas de intervenção organizadas em quatro eixos temáticos: Acessibilidade, Urbanidade, Seguridade e Sustentabilidade. Maiores detalhes sobre o processo de elaboração do Plano e seus desdobramentos podem ser encontrados em Tonucci Filho (2012) e no site http://www.rmbh.org.br.
} 
senvolvimento solidário - processo que, segundo Singer (2004), colocaria os povos no rumo da consolidação da economia solidária.

Este artigo pretende explorar essa questão, uma década após a elaboração e a aprovação do Plano, com o propósito de abordar, ainda, os limites e as potencialidades concretas para a economia popular tornar-se base desencadeadora de uma trajetória de desenvolvimento endógeno da metrópole. Com base no entendimento de que ainda não se consolidou uma ação coordenada voltada à economia popular na metrópole, propõe-se um retorno às propostas e possibilidades apresentadas pelo PDDI-RMBH, pois são múltiplas as oportunidades não aproveitadas e é premente a necessidade de repensar o modelo de desenvolvimento que recai sobre o território.

A primeira seção do artigo discute o desenvolvimento endógeno como paradigma possível e suas relações com a economia popular, a economia solidária e o desenvolvimento solidário. Em seguida, aborda-se a forma como se insere a ideia de economia popular e solidária nas propostas do PDDI-RMBH. Na terceira seção, o tema principal é o PDDI-RMBH e a proposta de uma "novíssima economia mineira”. Apresenta-se, na quarta seção, uma análise descritiva da economia popular em Minas Gerais - partindo de uma adaptação de categorias dos censos demográficos de 2000 e 2010 (IBGE). Com base nessas reflexões, a quinta seção discute as possibilidades efetivas para a economia popular, por meio da revisita a algumas propostas ainda não implementadas do Plano, mas que avançaram no período subsequente à sua aprovação. As considerações finais revisitam a questão central do artigo e apontam encaminhamentos possíveis.

\section{O desenvolvimento endógeno como paradigma}

Terminada a Segunda Guerra Mundial, aparece com maior centralidade no debate econômico internacional a ideia do subdesenvolvimento. De acordo com a teoria econômica vigente até então, o livre comércio internacional geraria naturalmente um processo de especialização produtiva entre os países, com a decorrente distribuição equitativa e justa dos resultados e dos ganhos do progresso tecnológico e científico.

Apesar de se observar, com efeito, um processo de especialização entre o Norte e o Sul global, a hipótese da distribuição dos ganhos não se concretizou. $\mathrm{O}$ Norte global avançava rapidamente na produção de mercadorias com alto valor tecnológico agregado, enquanto o Sul ficava restrito à produção de bens primários e de baixo valor agregado. A distribuição dos ganhos e do produto econômico mundial seguia, também, uma tendência desigual e que sempre favorecia os países do Norte. O subdesenvolvimento aparece então como condição de inserção dos países 
periféricos na dinâmica econômica internacional, responsável pela produção de uma série de desajustes nessas economias: inflação estrutural, deterioração dos termos de troca, crescimento da dívida externa, entre outros.

A busca da superação dessa condição é parte importante da história brasileira recente e está fundamentalmente ligada à escola do estruturalismo latino-americano cepalino. A Comissão Econômica para a América Latina e Caribe (Cepal) foi fundada em 1948 por um grupo de economistas latino-americanos com o objetivo de compreender justamente essa forma específica de inserção na economia global. Dentre uma série de diagnósticos realizados por esse grupo (RODRÍGUEZ, 2009 [2006]), um deles é particularmente importante para se pensar o presente trabalho: a relação entre a civilização industrial e a dependência cultural dos países periféricos.

O conceito de civilização industrial foi criado por Celso Furtado (1978) para caracterizar a sociabilidade e a cultura originadas nos países europeus. Na constituição dessa civilização, o autor ressalta o papel das revoluções industrial e científica e da revolução burguesa como bases culturais - visto que é por intermédio desses processos que identificamos o nascimento de uma cultura centrada i) na razão e na ciência moderna; ii) na inovação e na produção de meios de produção (e menos em produtos de consumo); e iii) na busca de poder econômico como forma de realização do poder político.

Para Furtado (1978), o desenvolvimento econômico capitalista ditado por essas economias centrais é responsável por difundir para o restante do mundo uma cultura essencialmente provinciana, isto é, particular desses países europeus. $\mathrm{O}$ efeito principal desse movimento é a expansão de uma cultura fundamentada na mercantilização da vida, na acumulação e no lucro como fins próprios do processo de desenvolvimento e no consumo baseado em bens tecnológicos. Essa cultura, quando exportada, funde-se à do país a que se endereça, produzindo mutações na racionalidade e no comportamento dos indivíduos em questão.

Nesse cenário, o desenvolvimento aparece sempre como um desenvolvimento exógeno, porque impõe sobre a economia dos países afetados imperativos econômicos que não necessariamente condizem com suas potencialidades e interesses internos. O desenvolvimento econômico capitalista, dada sua perspectiva eurocêntrica, consiste sempre em perda de autonomia dos indivíduos envolvidos no processo, uma vez que desconsidera caraterísticas históricas e sociais fundamentais destes e designa o desenvolvimento e a acumulação como fins em si mesmos, por meio da instrumentalização do discurso econômico. Para os economistas e teóricos cepalinos, a superação do subdesenvolvimento passa pela superação do paradigma exógeno do desenvolvimento - e, portanto, pela elaboração de uma perspectiva de 
desenvolvimento endógena. Essa endogeneidade deve ser entendida, então, como "a faculdade que possui uma comunidade humana de ordenar o processo de acumulação em função de prioridades por ela mesma definidas” (FURTADO, 1984). O desenvolvimento endógeno traz em si uma perspectiva emancipatória, na medida em que confere aos indivíduos e países a possibilidade de intervir e (re)orientar o processo de desenvolvimento - "o atributo de endogeneidade alude deste modo à necessidade de que os fins do desenvolvimento respondam às prioridades que cada sociedade estabeleça” (RODRÍGUEZ, 2009 [2006], p. 436).

A influência do pensamento cepalino na teoria econômica latino-americana se traduz, assim, em um esforço de "endogeneizar" o desenvolvimento econômico, social e espacial mediante a ação política guiada. Já na segunda metade do século $\mathrm{XX}$, entra em pauta no universo de políticas de desenvolvimento, como parte dessa nova orientação endógena, uma forte influência das configurações do território na conformação da estrutura econômica produtiva. Em especial, a dimensão local torna-se um objeto constante nas tentativas de induzir o desenvolvimento por meio de políticas específicas.

Até a década de 1970, o planejamento regional e urbano era baseado em uma perspectiva keynesiana top-down. Os territórios e as regiões não tinham muita autonomia na definição da atividade produtiva, uma vez que o Estado era responsável por coordenar e orientar o desenvolvimento regional ancorado em uma perspectiva de realização da demanda. Com a influência cepalina e com base na perspectiva endógena de desenvolvimento, as políticas de planejamento regional e urbano passam a ser orientadas por uma perspectiva bottom-up, em que o foco do desenvolvimento se situa "na produtividade endógena das economias regionais e locais" - isto é, em suas potencialidades e capacidades internas ${ }^{2}$ (DINIZ; CROCCO, 2006, p. 13).

Esse grupo de políticas faz parte da "segunda geração de políticas regionais" fundamentalmente ligadas a um enfoque de competitividade. Territórios e regiões eram orientados a considerar suas capacidades próprias de desenvolvimento e se desenvolver economicamente como forma de se apropriar dos ganhos econômicos

\footnotetext{
2. De acordo com Diniz e Crocco (2006, p. 13-14), “essa mudança de concepção de política tem sua origem em uma gama variada de fatores, que podem ser sintetizados em três grandes blocos: a) mudanças teóricas e ideológicas na concepção e no papel do Estado, criticando a excessiva intervenção deste e advogando sua retirada; b) críticas teóricas e empíricas ao pequeno alcance social das políticas regionais, resgatando a questão das classes sociais nos padrões do desenvolvimento capitalista; e c) desafio dos fenômenos não explicados pela teoria anterior, a exemplo dos processos de desindustrialização e crise dos padrões fordistas de organização produtiva, das mudanças na divisão internacional do trabalho e da emergência dos NICs - Newly Industrialized Countries -, de novos padrões tecnológicos e novas regiões produtivas".
} 
- não mais dependentes e orientados unicamente por uma perspectiva de desenvolvimento ecoada pelo Estado. Apesar da orientação endógena dessas políticas, a reivindicação da autonomia desses territórios se traduziu em uma tendência neoliberal de Estado Mínimo, desarticulando as estratégias de desenvolvimento dos níveis local, regional e nacional.

É nesse sentido que, a partir dos anos 1990, surge, como uma síntese mediadora, uma "terceira geração de políticas regionais". Também influenciado pela noção cepalina de desenvolvimento endógeno, esse grupo de políticas desponta como uma possível conciliação entre a busca pela autonomia local e territorial e um planejamento setorial e estatal coordenado. Nesse contexto apresentam-se, por exemplo, as políticas de estímulo à estruturação de sistemas regionais de inovação e de arranjos produtivos locais, que aliam as ações de desenvolvimento horizontais (locais e territoriais) às ações e orientações verticais (regionais, setoriais e [inter] nacionais).

Para Diniz e Crocco (2006, p. 14), essa mudança vem do entendimento de que “as políticas de desenvolvimento não podem ser exclusivamente locais” em um contexto de globalização, uma vez que uma orientação excessivamente exógena isto é, ditada pela dinâmica econômica dos países centrais - não é sustentável no longo prazo. Assim, essa terceira geração avança no sentido de criar uma racionalidade sistêmica, em que a dimensão endógena se torna fundamental no processo de desenvolvimento emancipatório.

No presente trabalho, tratamos do PDDI-RMBH, elaborado no contexto dessa terceira geração de políticas regionais. O Plano sugere uma leitura inovadora dos processos produtivos na metrópole e das possibilidades de desenvolvimento regional, pois, ao mesmo tempo que propõe o fortalecimento do papel econômico regional e nacional da RMBH, assume também a presença e a necessidade de fortalecimento da economia de base popular, fortemente ancorada no nível local e, portanto, em uma perspectiva endógena. Na terceira seção deste artigo, discutiremos mais a fundo o modo como o PDDI-RMBH relaciona a economia popular com a possibilidade de um desenvolvimento endógeno, mas, antes, faz-se necessário comentar as relações que podem ser construídas entre desenvolvimento endógeno, economia popular e solidária e desenvolvimento solidário.

\section{A tese da economia popular e o desenvolvimento endógeno como desenvolvimento solidário}

A ideia de um setor atrasado, de baixa produtividade e baixa capacidade técnico-científica, fadado ao desaparecimento no curso do processo de desenvolvimento, é parte da noção de desenvolvimento clássica elaborada nos países centrais. 
Na América Latina, e nos países periféricos de modo geral, o que se viu foi a persistência desse setor e sua tendência a cumprir um papel funcional na dinâmica capitalista (mão de obra barata, complementaridades setoriais, etc.). No século XX, essa noção sofre um importante questionamento; em particular, surge no campo dos Estudos Urbanos uma literatura que busca compreender como o processo de modernização das economias periféricas ocorre de maneira incompleta e seletiva e como o chamado "setor tradicional" passa a se relacionar em uma dinâmica inteiramente nova nas economias urbanas desses países (OLIVEIRA, 2003 [1972]; SANTOS, 2008 [1979]; RAZETO, 1993; CORAGGIO, 1994).

Nesse cenário, surge a tese de uma economia popular para explicar um conjunto de práticas realizadas pelos trabalhadores e trabalhadoras, que são ressignificadas no contexto de reestruturação produtiva e de urbanização extensiva e que assumem um papel fundamental na economia dos países periféricos (MONTE-MÓR, 2008; DINIZ, 2019). Em contraposição às análises dualistas - "setor tradicional", "setor de subsistência", "economia informal”, etc. -, a categoria da economia popular pretende justamente apreender o que há de específico no funcionamento desse setor que não permite seu desaparecimento no curso do desenvolvimento (RAZETO, 1993; CORAGGIO, 1994, 2000).

A economia popular é definida como o conjunto de atividades econômicas e práticas sociais desenvolvidas pelos membros das classes trabalhadoras como resultado do uso da própria força de trabalho e de recursos próprios. Tais atividades se destinam a prover e repor os meios de vida, agregando unidades de trabalho, sem se orientar para a inversão de capital (KRAYCHETE, 2006). Essa economia se baseia no trabalho familiar, por conta própria, artesanal, na autoconstrução da moradia, na economia camponesa. Sua dinâmica combina a produção doméstica com as relações mercantis, em uma conexão difusa entre valores de uso e valores de troca e que não se caminha para o desaparecimento nem para a desconexão com o mercado. O trabalho é o principal fator produtivo dessas unidades, cuja organização interna passa pela produção associada (cooperativas, associações, grupos de compra, sistemas de troca locais), pequenos negócios familiares e pelo trabalho individual (autônomos, “conta própria”), voltados ou não ao mercado.

Lisboa (2004) identifica Milton Santos como o precursor da categoria economia popular, pois esta retoma um conjunto de características que o autor atribui ao circuito inferior da economia urbana. Para Milton Santos (2008 [1979]), contrariamente ao que assume a dicotomia formal-informal, não se trata de tomar como ponto de partida a existência de um conjunto de decisões racionais e coordenadas (setor avançado) em oposição a outro grupo de ações supostamente irracionais e incorretas (setor atrasado). Ao contrário, o circuito inferior da economia (econo- 
mia popular, doméstica, do trabalho, etc.) também é provido de uma racionalidade própria que compõe um conjunto de racionalidades econômicas múltiplas que definem as economias periféricas.

Dentro desse conjunto de racionalidades, existe uma interseção, que buscamos ressaltar aqui, entre economia popular e economia solidária. A solidariedade é um atributo e uma forma de agir presente em certas atividades econômicas que reorienta a atividade produtiva para outros fins - em que o lucro e a acumulação não se constituem em sua justificativa e principal orientação. Nem toda economia popular é de solidariedade, tampouco a economia de solidariedade é necessariamente popular (RAZETO, 1993), uma vez que, na prática econômica, a solidariedade pode se verificar também em outros âmbitos, como na economia pública ou na economia privada 3 . Mas existiria "na economia popular embriões do que pode ser uma economia solidária, pois nas práticas dos setores populares encontramos uma racionalidade econômica fundada no trabalho e na cooperação" (LISBOA, 2004, p. 15).

A economia solidária consiste em uma proposta e em um projeto de emancipação centrado no trabalho, na cooperação e na reprodução ampliada da vida. Parte do princípio de que é possível produzir economicamente e redistribuir os ganhos desse processo de forma equitativa e justa, retirando o imperativo de acumulação do centro da análise do processo econômico. Para Singer (2002), a economia solidária pode se constituir em outro modo de produção, alternativo ao capitalismo, que se fundamente no trabalho e nas potencialidades dos indivíduos para construir uma forma associada e coletiva de crescimento e desenvolvimento econômico.

No desenvolvimento econômico clássico (exógeno), vemos uma forte tendência de a atividade econômica se orientar para a competição e para a eficiência. Como buscamos mostrar acima, quando importada para os países periféricos, essa noção de desenvolvimento não desempenha o mesmo papel que nos países centrais e, na maioria dos casos, agrava uma série de disparidades preexistentes nessas economias. Em contraposição a essa noção, Paul Singer (2004, p. 11) argumenta que a economia solidária permite antever um processo de desenvolvimento que não se opõe aos interesses coletivos e que possibilitaria "tornar o desenvolvimento mais justo, repartindo seus benefícios e prejuízos de forma mais igual e menos casual”.

O desenvolvimento solidário, expressão criada por esse autor, seria um processo capaz de manter a eficiência econômica, mas orientando o próprio processo produtivo para outra racionalidade. Por mais estranha que a questão da eficiên-

3. Para uma discussão a respeito das formas de solidariedade presentes nesses setores, cf. Coraggio (2013). 
cia produtiva possa soar - dada a relação intrínseca entre a produtividade e seu conteúdo determinístico, sua pretensa neutralidade e seu caráter poupador de trabalho (DAGNINO, 2014) -, aqui se trata justamente de uma eficiência sobre outras bases, no que diz respeito tanto à organização (a tomada de decisão, os rumos e os fins) como ao próprio significado da produção (não mais como acumulação e geração de lucro).

Assim, podemos ver uma aproximação da proposta de Singer à dos economistas e teóricos cepalinos, na medida em que seus discursos endereçam uma reorientação da atividade econômica e do crescimento como um meio, e não como um fim em si mesmo, submetendo-os ao crivo da ordem social (solidária) que passaria a existir. Nessa nova trajetória, os empreendimentos econômicos solidários (associações, cooperativas, grupos autogestionários) seriam os responsáveis pela mudança rumo ao progresso tecnológico - que deixaria de "ser produto da competição intercapitalista” e serviria, então, à "satisfação de necessidades consideradas prioritárias pela maioria” (SINGER, 2004, p. 7). Em síntese: o desenvolvimento solidário seria o "processo de fomento de novas forças produtivas e de instauração de novas relações de produção", com vistas a promover um "processo sustentável de crescimento econômico, que preserve a natureza e redistribua os frutos do crescimento a favor dos que se encontram marginalizados da produção social e da fruição dos resultados da mesma” (ibid). Isso significaria apostar na criatividade e nas virtudes pessoais inseridas na economia popular.

Apontamos, nesta seção, a proximidade entre a proposta de desenvolvimento endógeno e a de desenvolvimento solidário. Este último pode materializar a proposta de endogeneização do processo de desenvolvimento, tendo em vista que a economia popular, virtualmente solidária, aparece como possibilidade de promover "outro desenvolvimento": autônomo, solidário e orientado para os interesses e as potencialidades internas dos sujeitos que participam do processo.

\section{O PDDI-RMBH e a proposta de uma "novíssima economia mineira"}

O PDDI-RMBH tem sido identificado como um projeto capaz de promover um desenvolvimento territorial inovador em diversos aspectos (TONUCCI FILHO, 2012; TONUCCI FILHO; MONTE-MÓR, 2013; DINIZ; MONTE-MÓR, 2013; MONTE-MÓR et al., 2016). Entre as diretrizes gerais estabelecidas no Plano, encontra-se o direcionamento de ações para uma mudança da matriz produtiva da metrópole, no sentido, por um lado, da incorporação de tecnologias e do desenvolvimento de serviços avançados e de baixo impacto ambiental e, por outro, do estímulo à produção em pequena escala, de base popular. Esse conjunto de esforços estaria direcionado à 
redução das desigualdades socioespaciais e à valorização das identidades culturais da metrópole (UFMG, 2011).

Dessa forma, são exemplos de questões a serem debatidas com vistas a colocar novamente a RMBH como opção locacional e diferenciada na atração de novos investimentos no cenário nacional: (1) fortalecimento regional e maior integração da RMBH com seu entorno; (2) partição mais equitativa da receita tributária na RMBH; (3) criação de novos nichos de desenvolvimento econômico, social e ambiental; (4) consolidação de capacitações em indústrias de alta tecnologia e limpas; e (5) utilização de energias e materiais renováveis que venham a contribuir para a mitigação de mudanças climáticas (UFMG, 2011, p. 19).

O estado de Minas Gerais, em especial suas áreas metropolitanas, recebe historicamente investimentos expressivos em setores tradicionais, como a mineração, a siderurgia, o mercado imobiliário e a indústria da construção civil, os serviços produtivos e de transporte, entre outros, alguns deles com roupagens contemporâneas, acompanhados de grandes obras públicas de infraestrutura e de suporte a serviços de caráter metropolitano. O grande movimento de criação de um parque industrial fordista em Minas Gerais, e em especial na RMBH, conduzido pelos governos nos anos 1960 e 1970, deu origem ao que ficou conhecido como a "nova industrialização mineira” (DINIZ, 1981). O necessário esforço para se adequar às novas indústrias motrizes pós-fordistas foi chamado, no PDDI, de "novíssima economia mineira”.

O PDDI-RMBH buscou, entre outros objetivos, compreender essa tendência e propor medidas para sua potencialização e seu direcionamento para objetivos mais amplos de sustentabilidade, acessibilidade, urbanidade e seguridade. Tendo como diretriz principal a construção de um processo de planejamento participativo, integrado e permanente, o Plano propõe que o desenvolvimento futuro da metrópole se ampare nos avanços tecnológicos e num novo enfoque às questões ambientais, e, ao mesmo tempo, integre as diversas porções do território, priorizando os espaços periféricos, e cumprindo os preceitos de redução das desigualdades socioespaciais e valorização das diversas identidades da Região Metropolitana (DINIZ; MONTE-MÓR, 2013, p. 2).

Interessa aqui destacar a resposta do PDDI-RMBH ao que Diniz e Crocco (2006) chamaram de "política regional de terceira geração" e ao novo paradigma do desenvolvimento endógeno. Não há, no entanto, uma definição unívoca e inquestionável para essa “novíssima economia” no documento. Apoiados na divisão ligada 
aos eixos temáticos do Plano, podemos identificar uma variação considerável de denominações conceituais para o que seria essa economia (VELLOSO; WOJCIECHOWSKI, 2015) ${ }^{4}$. No âmbito do que o Plano define como "produção de pequena escala", surge uma definição que, a nosso ver, é especialmente adequada e consistente com a proposta de desenvolvimento endógeno. Trata-se de um precedente de reflexões sobre a promoção de políticas indutoras de desenvolvimento endógeno que não se aplica apenas à RMBH, mas que diz respeito a uma reflexão sobre a economia mineira como um todo.

No texto do Plano, a novíssima economia mineira estaria condicionada a um processo de consolidação de uma economia popular solidária. Essa expectativa é encontrada em diversos momentos do diagnóstico, em menções a uma diversidade de atividades e formas organizativas, como a agricultura familiar e urbana, o turismo de base comunitária e a economia da cultura.

O entendimento geral do PDDI-RMBH é de que o trabalho e a renda são dimensões essenciais da vida cotidiana na metrópole, necessariamente integradas às demais questões que perpassam a cidadania. A produção em pequena escala é ressaltada por seu papel e seu potencial em prover trabalho e renda, em especial àquela população não absorvida diretamente pelos grandes investimentos previstos para a RMBH. Além disso, essa produção seria responsável por preservar as tradições culturais culinárias, de expressão estética, de organização do cotidiano, do trabalho e do modo de vida em geral.

Trata-se, portanto, da aplicação, para a política pública, da tese da existência de um duplo potencial emancipatório da economia popular. Por um lado, há um potencial sociopolítico e cultural de pautar outras formas de produzir e se reproduzir, tendo como base as formas cotidianas; e, por outro, um potencial de desenvolvimento endógeno, fortalecendo alternativas de (re)produção de base territorial, que busquem um desenvolvimento não predatório e não concentrador de renda. Assim, do ponto de vista das ações de planejamento territorial do setor público, das universidades ou dos movimentos da sociedade civil, seria imprescindível consi-

4. Como observam Velloso e Wojciechowski (2015, p. 410), a disputa em torno do sentido do horizonte de desenvolvimento é uma das principais questões que surgiram do PDDI: "O PDDI-RMBH tensionou a disputa em curso no estado de Minas Gerais, sobre os rumos da RMBH, ao combinar o esforço da projetação do desenvolvimento sustentável e inclusivo, o investimento em setores produtivos privilegiados, e a meta da redução de desigualdades socioespaciais, sem, contudo, resolver ou reduzir essa disputa a termos manejáveis e cabíveis à esfera do planejamento urbano. A metrópole tornada competitiva no cenário de investimentos brasileiro é um pensamento de distante alcance para as camadas populares da sociedade ainda que se conte com posteriores efeitos de irradiação desse crescimento/desenvolvimento em áreas e estratos sociais menos favorecidos. O plano nunca pretendeu resolver esse conflito interno às suas proposições, pelo contrário e, ao fim e ao cabo, muito da sua radicalidade talvez resida na opção que faz por apresentar esse duplo caminho como horizonte de construção da metrópole”. 
derar o desenvolvimento e o fortalecimento de oportunidades dentro da economia popular e/ou solidária. É possível entender, em decorrência, a orientação do Plano como uma das expressões de um movimento global que reivindica a construção da "outra economia" - "regida pelos princípios da solidariedade, da sustentabilidade, da inclusão, enfim, da emancipação social”, princípios que "não se reduzem a boas intenções, mas constituem realizações concretas, viáveis e, sobretudo, em expansão no mundo inteiro" (SINGER, 2004, p. 7).

Entende-se que as organizações e os fluxos que compõem a economia popular, responsáveis por boa parte da reprodução das famílias, serão fundamentais para promover melhores condições para a inclusão social e econômica delas, em consonância com as múltiplas oportunidades criadas pelos novos investimentos previstos para a metrópole (UFMG, 2011). Na visão do Plano, a reestruturação territorial metropolitana, em especial dos espaços destinados a práticas cooperativas e solidárias, deveria pautar-se por uma integração entre a economia capitalista hegemônica, a economia da pequena produção popular e solidária e o setor público. A constituição e o fortalecimento de centralidades espaciais (em suas diversas escalas) passariam por essa integração, na busca de espaços sociais mais diversificados e menos segregados. O fomento dessas espacialidades seria a base para planos de desenvolvimento pautados na redução das desigualdades, no crescimento das iniciativas capazes de integrar a população no cotidiano econômico e cultural e permitir a viabilidade econômica diante dos limites ambientais, partindo de uma visão integrada, em contraposição à visão setorial em geral adotada. Assim, o grande desafio proposto pelo PDDI-RMBH é a construção de um novo modo de pensar e planejar a metrópole, com a inversão de prioridades, em um processo de integração e de (re)construção do território.

Desse modo, o fortalecimento de uma economia solidária de base popular surge no PDDI como um horizonte possível de desenvolvimento endógeno no capitalismo pós-fordista. Essa questão nos leva, então, a discutir com maior precisão o real significado do termo economia popular no contexto de Minas Gerais.

\section{A economia popular mineira a partir dos censos demográficos}

Os resultados apresentados a seguir resultam da aplicação de uma metodologia de identificação da economia popular nos dados dos censos demográficos brasileiros. Para essa construção, adaptou-se a tipologia de Hirata e Machado (2007) para o setor informal, com a finalidade de se chegar a uma aproximação da economia popular. São combinadas informações do setor de ocupação do trabalha- 
dor com sua posição na ocupação e, ainda, a composição do trabalho na família. $\mathrm{O}$ detalhamento dessa construção metodológica pode ser encontrado em Diniz (2016).

O Quadro 1 resume o procedimento de chegada a essas unidades produtivas, que foram assim denominadas: i) unidade doméstica individual, quando o trabalhador atua sozinho em relação aos demais membros do domicílio; ii) unidade doméstica familiar, quando mais de um trabalhador do domicílio atua na mesma ocupação ou em ocupações próximas5.

\begin{tabular}{|l|l|}
\hline Unidade produtiva & $\begin{array}{l}\text { Construção baseada nas variáveis de ocupação dos censos } \\
\text { demográficos }\end{array}$ \\
\hline $\begin{array}{l}\text { Unidade doméstica } \\
\text { individual }\end{array}$ & - Trabalhador por conta própria atuando sozinho; \\
\cline { 2 - 3 } & - Trabalhador para o próprio consumo atuando sozinho. \\
\hline \multirow{5}{*}{$\begin{array}{l}\text { Unidade doméstica } \\
\text { familiar }\end{array}$} & $\begin{array}{l}\text { - Trabalhadores por conta própria (dois ou mais) do mesmo } \\
\text { domicílio atuando na mesma ocupação ou em ocupações } \\
\text { próximas; }\end{array}$ \\
\cline { 2 - 3 } & $\begin{array}{l}\text { - Trabalhador(es) por conta própria do mesmo domicílio atuando } \\
\text { na mesma ocupação ou em ocupações próximas, com o auxílio } \\
\text { de trabalhador(es) não remunerado(s); }\end{array}$ \\
\cline { 2 - 3 } & $\begin{array}{l}\text { - Trabalhadores na produção para o próprio consumo (dois ou } \\
\text { mais) do mesmo domicílio atuando na mesma ocupação ou em } \\
\text { ocupações próximas; }\end{array}$ \\
\cline { 2 - 3 } & $\begin{array}{l}\text { - Empregador(es) do mesmo domicílio atuando na mesma } \\
\text { ocupação ou em ocupações próximas, com o auxílio de traba- } \\
\text { Ihador(es) não remunerado(s) ou empregado(s) sem carteira } \\
\text { residentes no domicílio e em ocupações próximas. }\end{array}$ \\
\hline
\end{tabular}

Quadro 1. Construção do recorte da economia popular, segundo unidades domésticas. Fonte: Elaboração dos autores.

Grosso modo, a análise proposta baseia-se na divisão dos trabalhadores ocupados em cinco grandes grupos:

1. A economia popular, composta de unidades domésticas individuais ou familiares, segundo a descrição presente no Quadro 1.

2. A economia informal, composta de trabalhadores assalariados sem carteira de trabalho assinada e trabalhadores na produção para consumo próprio que não foram considerados parte da economia popular ${ }^{6}$.

3. Os trabalhadores domésticos.

5. Como ocupações próximas, são consideradas as ocupações dentro de cada grupo definido no Quadro 2, apresentado adiante.

6. Note-se que a tipologia utilizada tem o intento de diferenciar a economia popular da economia informal. A distinção principal da economia popular estaria na racionalidade interna às unidades produtivas, 
4. A economia formal, composta de trabalhadores assalariados com carteira de trabalho assinada e de profissionais liberais.

5. A economia do setor público, composta de trabalhadores estatutários e de militares.

O foco do exercício empírico recai sobre as unidades produtivas de pequeno porte amparadas no fundo de trabalho e em recursos próprios. Acredita-se que esse conjunto de trabalhadores se aproxima das definições de Razeto (1993), Coraggio (1994, 2000) e Tiriba (2003) para a economia popular, uma vez que se mostra compatível com as seguintes características:

- Realização do exercício do trabalho a partir de meios de produção próprios, podendo contar com mão de obra familiar;

- Escala de organização pequena o suficiente para admitir relações econômicas interpessoais, não necessariamente intermediadas pelo mercado e pela concorrência;

- Ausência de uma relação sistemática de emprego ou assalariamento;

- Remissão a unidades produtivas que se amparam no fundo de trabalho, em que os meios de produção são muitas vezes parte da reprodução familiar, inseridos em redes de cooperação intra e interdomiciliares.

Considerando ainda a grande heterogeneidade de ocupações dentro do recorte adotado, assumiu-se uma divisão em três grupos, apresentada no Quadro 2.

\begin{tabular}{|c|c|c|}
\hline Grupos de análise & Grupo de ocupações & $\begin{array}{l}\text { Ocupaç̃̃es consideradas } \\
\text { (CBO-Domiciliar - Censos } \\
\text { 2000 e 2010) }\end{array}$ \\
\hline $\begin{array}{l}\text { Economia popular } \\
\text { - Grupo } 1\end{array}$ & $\begin{array}{l}\text { Trabalhadores da agropecuária, florestais, } \\
\text { da caça e da pesca }\end{array}$ & 6.110 a 6.430 \\
\hline \multirow{2}{*}{$\begin{array}{l}\text { Economia popular } \\
\text { - Grupo } 2\end{array}$} & \multirow{2}{*}{$\begin{array}{l}\text { Trabalhadores dos serviços e vendedores } \\
\text { dos comércios e mercados }\end{array}$} & 3.761 a 3.764 \\
\hline & & 5.101 a 5.243 \\
\hline $\begin{array}{l}\text { Economia popular } \\
\text { - Grupo } 3\end{array}$ & $\begin{array}{l}\text { Trabalhadores da construção, das artes } \\
\text { mecânicas, do artesanato, da fabricação } \\
\text { de alimentos e confecções }\end{array}$ & 7.101 a 9.922 \\
\hline
\end{tabular}

Quadro 2. Descrição dos grupos de análise na economia popular.

Fonte: Elaboração dos autores.

voltada à própria reprodução e diretamente relacionada a outros princípios de organização econômica, para além do mercado. Para Tiriba (2003), uma característica intrínseca à economia informal é a exploração da força de trabalho dos que não possuem os meios de produção. Nesse sentido, pode-se dizer que a economia popular apresenta pontos de interseção com a economia informal, embora não se confunda com esta. 
O conjunto de trabalhadores na economia popular em Minas Gerais, segundo o recorte adotado, reunia 1,5 milhão de pessoas em 2000, correspondendo a 21,6\% do total de ocupados no estado. Esse grupo cresceu em termos absolutos e chegou, em 2010, a 1,7 milhão de trabalhadores e 17,8\% dos ocupados (Tabela 1).

\begin{tabular}{|c|c|c|c|c|c|c|c|c|c|}
\hline & & \multicolumn{3}{|c|}{2000} & \multicolumn{3}{|c|}{2010} & \multicolumn{2}{|c|}{$2000-2010$} \\
\hline & & $\underset{\text { milhares }}{\mathrm{Em}}$ & $\%$ & $\begin{array}{c}\% \\
\text { acum. }\end{array}$ & $\begin{array}{c}\text { Em } \\
\text { milhares }\end{array}$ & $\%$ & $\begin{array}{c}\% \\
\text { acum. }\end{array}$ & $\begin{array}{c}\text { Em } \\
\text { milhares }\end{array}$ & $\begin{array}{c}\text { Cresc. } \\
(\%)\end{array}$ \\
\hline \multirow{3}{*}{$\begin{array}{l}\text { Economia } \\
\text { popular }\end{array}$} & $\begin{array}{l}\text { Economia popular } \\
\text { - grupo } 1\end{array}$ & 551,3 & 7,7 & 7,7 & 703,1 & 7,6 & 7,6 & 151,7 & 27,5 \\
\hline & $\begin{array}{l}\text { Economia popular } \\
\text { - grupo } 2\end{array}$ & 467,6 & 6,5 & 14,2 & 368,6 & 4,0 & 11,6 & $-99,0$ & $-21,2$ \\
\hline & $\begin{array}{l}\text { Economia popular } \\
\text { - grupo } 3\end{array}$ & 522,8 & 7,3 & 21,6 & 579,5 & 6,3 & 17,8 & 56,7 & 10,8 \\
\hline $\begin{array}{l}\text { Trabalhadores } \\
\text { domésticos }\end{array}$ & Domésticos & 626,4 & 8,8 & 30,3 & 702,3 & 7,6 & 25,4 & 75,9 & 12,1 \\
\hline \multirow{2}{*}{$\begin{array}{l}\text { Economia } \\
\text { informal }\end{array}$} & $\begin{array}{l}\text { Assalariados sem } \\
\text { carteira }\end{array}$ & 1461,4 & 20,4 & 50,7 & 1477,3 & 16,0 & 41,4 & 16,0 & 1,1 \\
\hline & Outros $^{*}$ & 126,5 & 1,8 & 100,0 & 95,9 & 1,0 & 100,0 & $-30,6$ & $-24,2$ \\
\hline \multirow{2}{*}{$\begin{array}{l}\text { Economia } \\
\text { formal }\end{array}$} & $\begin{array}{l}\text { Assalariados com } \\
\text { carteira }\end{array}$ & 2468,7 & 34,5 & 85,3 & 4029,0 & 43,5 & 84,8 & 1560,3 & 63,2 \\
\hline & $\begin{array}{l}\text { Empregadores e } \\
\text { autônomos }\end{array}$ & 461,6 & 6,5 & 91,7 & 713,8 & 7,7 & 92,5 & 252,2 & 54,6 \\
\hline $\begin{array}{l}\text { Economia do } \\
\text { setor público }\end{array}$ & Setor público & 467,0 & 6,5 & 98,2 & 594,9 & 6,4 & 99,0 & 127,9 & 27,4 \\
\hline \multicolumn{2}{|l|}{ Total } & 7153,1 & 100,0 & & 9264,4 & 100,0 & & 2111,3 & 29,5 \\
\hline
\end{tabular}

Tabela 1. Trabalhadores da economia popular e em outras categorias de ocupação, Minas Gerais, 2000 e 2010.

* Não remunerados e produtores para o próprio consumo não incluídos no recorte adotado para a economia popular.

Fonte: Elaboração dos autores com base nos microdados dos censos demográficos de 2000 e 2010 (IBGE).

O Gráfico 1 apresenta a distribuição dos trabalhadores, em 2010, segundo recortes regionais. A participação da economia popular é mais significativa nas áreas rurais. Naquele ano, a economia popular correspondia a 10,6\% dos trabalhadores de Belo Horizonte, 12,6\% na RMBH e 13,9\% nas áreas urbanas. Note-se que a dinâmica dos Grupos 2 e 3 se diferencia consideravelmente entre as áreas urbanas e as rurais. 


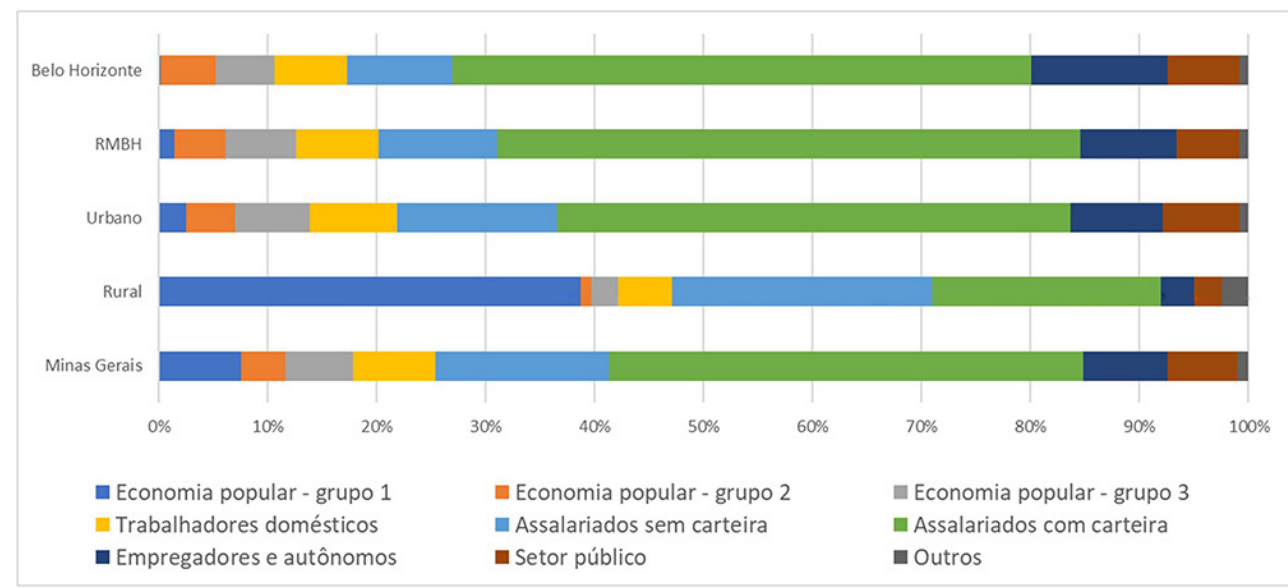

Gráfico 1. Distribuição dos trabalhadores por recortes regionais, Minas Gerais, 2010.

Fonte: Elaboração dos autores com base nos microdados do Censo Demográfico de 2010 (IBGE). Obs.: Os recortes "Urbano" e "Rural" dizem respeito à classificação do IBGE. Os dados apresentados para esses dois recortes se referem a todo o estado de Minas Gerais.

O Quadro 3, adiante, construído com base na tabela completa de ocupações com as respectivas participações, resume as principais ocupações encontradas no recorte adotado. Note-se a grande heterogeneidade de ocupações, inclusive dentro dos grupos analisados. As ocupações do Grupo 1 são ligadas predominantemente à agricultura e à pecuária. $\mathrm{O}$ Grupo 2 é dominado por vendedores do comércio $\mathrm{e}$ ambulantes, além de ocupações ligadas aos serviços de higiene e embelezamento. Já no Grupo 3, destacam-se as ocupações relativas à construção civil e também ao setor de confecções. Ao compararmos essas ocupações àquelas identificadas no Sistema de Informações em Economia Solidária (Sies)7, detectam-se algumas semelhanças, relacionadas em especial à agricultura, artesanato e confecções (DINIZ; ROCHA, 2019). Esse grupo de ocupações estaria, portanto, mais próximo do perfil de organização coletiva, em grupos informais, associações ou cooperativas ${ }^{8}$. Para os demais setores (construção civil, serviços pessoais [cuidados], transportes e mecânica de automóveis), em que não há experiência acumulada de trabalho coletivo, abrem-se possibilidades de organização em torno da economia solidária.

\footnotetext{
7. Dois mapeamentos nacionais foram realizados pela extinta Secretaria Nacional de Economia Solidária (Senaes), ligada ao também extinto Ministério do Trabalho e do Emprego (MTE). No segundo mapeamento, realizado entre 2009 e 2013, foram colhidas informações de 19.708 empreendimentos econômicos solidários no Brasil, 1.188 deles em Minas Gerais. Uma discussão sobre os mapeamentos, bem como sobre seus resultados e limites, pode ser encontrada em Gaiger (2012, 2013). GAIGER, L. I. G. Avances y límites en la producción de conocimientos sobre la economía solidaria en Brasil. In: CORAGGIO, J. L. (ed.). Conocimiento y políticas públicas de economía social y solidaria: problemas y propuestas. Quito: Editorial Iaen, 2012. GAIGER, L. I. G. O mapeamento nacional e o conhecimento da economia solidária. Revista da Associação Brasileira de Estudos em Trabalho, v. 12, n. 1, p.7-24, jan.-jun. 2013.
}

8. Sobre o perfil dos trabalhadores da economia solidária em Minas Gerais, ver Diniz e Rocha (2019). 


\begin{tabular}{|c|c|}
\hline Grupos de análise & Principais ocupações segundo o Censo Demográfico de 2010 \\
\hline $\begin{array}{l}\text { Economia popular } \\
\text { - Grupo } 1\end{array}$ & $\begin{array}{l}\text { Produtores e trabalhadores agrícolas; produtores e trabalhadores na } \\
\text { pecuária. }\end{array}$ \\
\hline \multirow{3}{*}{$\begin{array}{l}\text { Economia popular } \\
\text { - Grupo } 2\end{array}$} & $\begin{array}{l}\text { Trabalhadores do comércio: vendedores e demonstradores em lojas, } \\
\text { mercados; vendedores em quiosques e barracas; vendedores ambulan- } \\
\text { tes. }\end{array}$ \\
\hline & Trabalhadores dos serviços pessoais: embelezamento e higiene. \\
\hline & $\begin{array}{l}\text { Trabalhadores dos serviços de alimentação: cozinheiros, garçons e } \\
\text { copeiros. }\end{array}$ \\
\hline \multirow{4}{*}{$\begin{array}{l}\text { Economia popular } \\
\text { - Grupo } 3\end{array}$} & $\begin{array}{l}\text { Trabalhadores do setor de confecções: operadores de máquinas de } \\
\text { costura de roupas. }\end{array}$ \\
\hline & $\begin{array}{l}\text { Trabalhadores da construção civil e relacionados: trabalhadores de } \\
\text { estruturas de alvenaria, madeira, metal e compósitos; pintores de obras } \\
\text { e revestidores de interiores; encanadores e instaladores de tubulações; } \\
\text { marceneiros e afins; ajudantes de obras civis. }\end{array}$ \\
\hline & $\begin{array}{l}\text { Condutores de veículos: condutores e operadores polivalentes; condu- } \\
\text { tores de veículos sobre rodas (transporte particular e distribuidor de } \\
\text { mercadorias). }\end{array}$ \\
\hline & $\begin{array}{l}\text { Trabalhadores de reparação e manutenção: mecânicos de manutenção } \\
\text { de veículos automotores. }\end{array}$ \\
\hline
\end{tabular}

Quadro 3. Principais ocupações na economia popular, 2010.

Fonte: Elaboração dos autores com base nos microdados do Censo Demográfico de 2010 (IBGE).

A Tabela 2 apresenta as características sociodemográficas dos trabalhadores nos dois anos de análise. Em linhas gerais, os dados revelam os processos que envolvem o mercado de trabalho na década, como o aumento da participação da mulher, a elevação da idade média dos trabalhadores e dos níveis de escolaridade, além da formalização. Observa-se que, a despeito de a participação das mulheres ter crescido em todas as categorias de ocupação, o crescimento mais expressivo ocorreu nos três grupos da economia popular, para os trabalhadores sem carteira e para os empregadores e autônomos. A economia popular, o grupo de trabalhadores domésticos e os grupos da economia informal absorvem de forma muito significativa essa força de trabalho, o que pode estar relacionado tanto à associação do trabalho feminino a ocupações precárias quanto às possibilidades de trabalho em bases mais flexíveis, o que possibilitaria conciliar o cuidado com os filhos e parentes idosos com a realização das tarefas domésticas. 


\begin{tabular}{|c|c|c|c|c|c|c|c|c|c|c|c|c|c|}
\hline \multirow{2}{*}{$\begin{array}{l}\overline{\sqrt{\pi}} \\
\stackrel{0}{\circ}\end{array}$} & ㅇํํ & 仓̃ & $\begin{array}{l}\infty \\
\text { N } \\
\end{array}$ & $\stackrel{m}{m}$ & ஸे & $\stackrel{m}{5}$ & 壬 & & 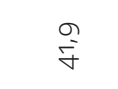 & $\stackrel{0}{\infty^{\circ}}$ & $\stackrel{m}{\infty_{N}^{n}}$ & $\stackrel{\infty}{=}$ & \\
\hline & $\begin{array}{l} \\
\\
\text { ¿े }\end{array}$ & $\stackrel{m}{m}$ & $\begin{array}{l}\circ \\
\stackrel{i v ̄}{+} \\
\end{array}$ & $\underset{\substack{f \\
m}}{ }$ & $\hat{\sigma}$ & 今ิ & $\begin{array}{l}0 \\
\dot{\sigma} \\
\dot{q}\end{array}$ & & $\stackrel{\bar{i}}{\mathrm{i}}$ & 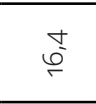 & $\begin{array}{l}\stackrel{N}{\sigma} \\
\sigma\end{array}$ & $\hat{\sigma}$ & \\
\hline \multirow{2}{*}{ 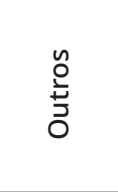 } & $\stackrel{\circ}{\grave{N}}$ & 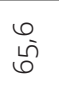 & min & $\stackrel{\stackrel{\llcorner}{f}}{\stackrel{m}{m}}$ & $\begin{array}{l}\infty \\
\text { Ñ }\end{array}$ & 怘 & $\stackrel{\substack{n \\
\infty}}{\stackrel{\infty}{\sim}}$ & & $\begin{array}{l}0 \\
\infty^{-} \\
\omega^{\prime}\end{array}$ & $\stackrel{\widehat{\infty}}{\stackrel{0}{\leftarrow}}$ & $\stackrel{\circ}{\stackrel{\infty}{\leftarrow}}$ & 字 & \\
\hline & $\begin{array}{l} \\
\vdots \\
\vdots \\
\text { N. }\end{array}$ & $\begin{array}{l}\stackrel{n}{n} \\
\text { 今n }\end{array}$ & $\stackrel{+}{\stackrel{f}{f}}$ & $\begin{array}{l}\infty \\
\infty_{N}^{-}\end{array}$ & $\hat{\tilde{N}}$ & $\stackrel{\circ}{\dot{\Sigma}}$ & $\begin{array}{l}\stackrel{2}{\circ} \\
\stackrel{9}{\circ}\end{array}$ & & $\begin{array}{l}0 \\
\hat{\omega} \\
0\end{array}$ & $\begin{array}{l}\stackrel{\infty}{\sim} \\
\stackrel{n}{\sim}\end{array}$ & 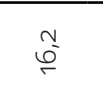 & $\stackrel{\sim}{\mathrm{N}}$ & \\
\hline \multirow{2}{*}{ 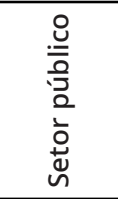 } & $\stackrel{\circ}{\grave{N}}$ & $\begin{array}{l}\infty \\
\tilde{b}\end{array}$ & 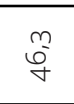 & $\hat{\bar{\sigma}}$ & Ñ & $\begin{array}{l}\infty \\
\text { 亏ે }\end{array}$ & $\stackrel{N}{O}_{\tilde{\sigma}}^{0}$ & & $\bar{m}$ & $\infty_{\infty}^{m}$ & $\stackrel{m}{m}$ & 离 & \\
\hline & \begin{tabular}{l}
$\circ$ \\
$:$ \\
\multirow{N}{*}{}
\end{tabular} & $\begin{array}{l}\stackrel{n}{2} \\
\stackrel{0}{6}\end{array}$ & $\stackrel{6}{\text { m }}$ & $\stackrel{\stackrel{n}{2}}{\stackrel{m}{m}}$ & ָ̃ & ڤે & $\begin{array}{c}\infty \\
\sigma_{+}^{-} \\
\sigma^{\prime}\end{array}$ & & 节 & $\underset{\stackrel{i}{\sim}}{ }$ & $\begin{array}{l}\infty \\
\dot{m}^{-} \\
m^{2}\end{array}$ & $\stackrel{\sim}{\sim}$ & \\
\hline \multirow{2}{*}{ 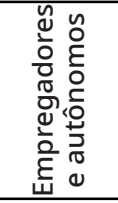 } & $\stackrel{\circ}{\grave{n}}$ & $\stackrel{\circ}{\stackrel{0}{m}}$ & $\begin{array}{l}0 \\
\tilde{m} \\
\text { m }\end{array}$ & \begin{tabular}{l}
0 \\
$\tilde{y}$ \\
\multirow{\gamma}{*}{}
\end{tabular} & $\begin{array}{l}\infty \\
\infty \\
\infty\end{array}$ & 忘 & $\stackrel{N}{N}$ & & 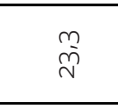 & $\stackrel{N}{\underset{f}{\tau}}$ & $\overline{\tilde{m}}$ & $\begin{array}{l}+ \\
\stackrel{+}{0} \\
\grave{n}\end{array}$ & \\
\hline & $\begin{array}{l}0 \\
\vdots \\
\vdots\end{array}$ & $\stackrel{\bar{o}}{\sim}$ & $\begin{array}{l}\text { gे } \\
\dot{N}\end{array}$ & $\begin{array}{l}\stackrel{\circ}{\dot{y}} \\
\dot{\dot{y}}\end{array}$ & $\begin{array}{l}0 \\
\infty \\
\infty \\
\infty\end{array}$ & 甬 & $\stackrel{N}{\widetilde{\sigma}}$ & & $\begin{array}{l}0 \\
\stackrel{0}{5} \\
\stackrel{5}{~}\end{array}$ & $\stackrel{\Im}{\mp}$ & $\stackrel{+}{N}$ & $\begin{array}{l}\stackrel{N}{\sim} \\
\stackrel{N}{N}\end{array}$ & \\
\hline \multirow{2}{*}{ 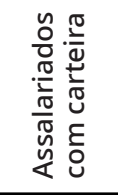 } & ○ํ. & $\stackrel{\circ}{\stackrel{0}{m}}$ & 节 & $\stackrel{\llcorner}{f}$ & $\begin{array}{l}0 \\
\dot{a}\end{array}$ & $\begin{array}{l}\infty \\
\text { ì } \\
\text { ஸे }\end{array}$ & $\stackrel{\circ}{\grave{y}}$ & & $\stackrel{\circ}{\text { N }}$ & $\stackrel{\text { }}{\sigma}$ & $\hat{\hat{\sigma}}$ & 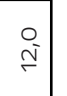 & \\
\hline & $\begin{array}{l} \\
\vdots \\
\vdots \\
\end{array}$ & 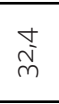 & $\stackrel{\sigma}{f}$ & $\stackrel{\substack{n \\
m}}{m}$ & $\begin{array}{l}\text { ò } \\
\dot{\sigma}\end{array}$ & 灾 & 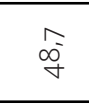 & & $\begin{array}{c}N \\
\infty^{\infty} \\
+\end{array}$ & $\stackrel{\text { No }}{\text { ğ }}$ & 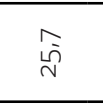 & $\stackrel{\circ}{=}$ & \\
\hline \multirow{2}{*}{ 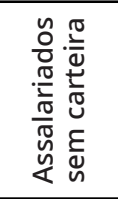 } & ○ & $\stackrel{\bullet}{\stackrel{m}{m}}$ & 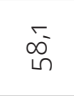 & $\underset{\mathrm{f}}{\mathrm{f}}$ & స్̄ & $\begin{array}{l}\text { t' } \\
0 \\
0\end{array}$ & 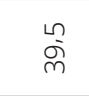 & & กิ & $\stackrel{+}{\sigma}$ & $\stackrel{\circ}{\grave{N}}$ & $\stackrel{\infty}{i}$ & \\
\hline & 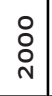 & $\begin{array}{l}\infty \\
0^{-} \\
\sim^{-1}\end{array}$ & $\begin{array}{l}\text { o } \\
\text { in }\end{array}$ & $\stackrel{t}{\stackrel{ \pm}{m}}$ & $\tilde{\tilde{v}}$ & $\begin{array}{l}m \\
0 \\
0\end{array}$ & $\stackrel{m}{m}$ & & $\begin{array}{l}\qquad n \\
\infty \\
0 \\
0\end{array}$ & $\begin{array}{l}0 \\
\stackrel{0}{\circ}\end{array}$ & $\begin{array}{l}\infty \\
\stackrel{\infty}{\sim}\end{array}$ & $\begin{array}{l}0 \\
i\end{array}$ & \\
\hline \multirow{2}{*}{ 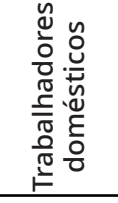 } & \begin{tabular}{l} 
\\
\multirow{2}{*}{} \\
\end{tabular} & $\begin{array}{l}\text { ळे } \\
\text { مे }\end{array}$ & $\begin{array}{l}\infty \\
0 \\
\tilde{N}\end{array}$ & $\begin{array}{l}\dot{0} \\
\infty_{m}^{0}\end{array}$ & $\begin{array}{l}N \\
\text { N }\end{array}$ & $\stackrel{i}{i}$ & $\stackrel{\wedge}{\bar{m}}$ & & 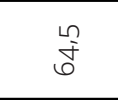 & $\begin{array}{l}0 \\
\text { ì }\end{array}$ & $\stackrel{\llcorner}{\underset{f}{\ddagger}}$ & $0_{0}^{t}$ & \\
\hline & $\begin{array}{l} \\
\vdots \\
\vdots \\
\text { N }\end{array}$ & ๙̀ & $\begin{array}{l}0 \\
8\end{array}$ & $\bar{i}$ & $\tilde{\tilde{N}}$ & 突 & $\stackrel{\infty}{\bar{\sim}}$ & & $\stackrel{\circ}{\stackrel{\circ}{\wedge}}$ & $\begin{array}{l}\infty \\
\stackrel{\infty}{\sigma}\end{array}$ & $\bar{\sigma}$ & $\overline{0}$ & \\
\hline \multirow{2}{*}{ 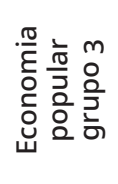 } & $\stackrel{\circ}{\circ}$ & $\stackrel{\bar{\alpha}}{\sim}$ & $\stackrel{\text { 足 }}{\mathrm{f}}$ & 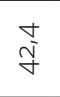 & $\stackrel{n}{\sigma}$ & $\begin{array}{l}\infty \\
\stackrel{\infty}{0} \\
\text { in }\end{array}$ & $\begin{array}{l}\text { N } \\
\text { ऽે }\end{array}$ & & 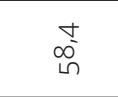 & $\begin{array}{l}\text { ô } \\
\text { ì }\end{array}$ & $\stackrel{N}{\sigma}$ & $\stackrel{\stackrel{n}{=}}{=}$ & 8 \\
\hline & $\begin{array}{l} \\
\vdots \\
\vdots \\
\end{array}$ & $\begin{array}{l}n \\
\underline{n} \\
\underline{\sigma}\end{array}$ & $\begin{array}{l}\infty \\
\dot{f} \\
\dot{f}\end{array}$ & ڤे & ন্ & 䆚 & \begin{tabular}{l} 
\\
\multirow{f}{*}{} \\
\end{tabular} & & $\widehat{N}$ & $\stackrel{m}{\stackrel{n}{0}}$ & $\stackrel{m}{\stackrel{m}{\circ}}$ & $\begin{array}{l}0 \\
0 \\
0\end{array}$ & \\
\hline \multirow{2}{*}{ 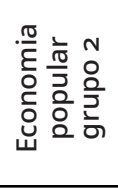 } & $\stackrel{\circ}{\stackrel{N}{N}}$ & 亏ั. & $\begin{array}{c}m \\
\text { ò } \\
\text { in }\end{array}$ & $\begin{array}{l}0 \\
0 \\
\dot{q}\end{array}$ & $\begin{array}{l}\infty \\
\searrow \\
\infty\end{array}$ & 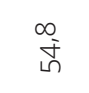 & $\stackrel{\wp}{f}$ & & $\overline{\tilde{y}}$ & $\widehat{\widetilde{N}}$ & $\begin{array}{l}\sigma \\
\stackrel{a}{m} \\
\dot{m}\end{array}$ & $\stackrel{+}{+}$ & \\
\hline & 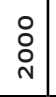 & 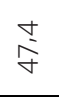 & $\stackrel{N}{\text { m }}$ & j̀ & 今) & $\stackrel{n}{i}$ & 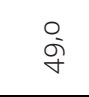 & & $\stackrel{\Omega}{i}$ & $\stackrel{m}{\sigma}$ & 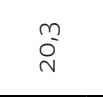 & $\stackrel{n}{v}$ & \\
\hline \multirow{3}{*}{ 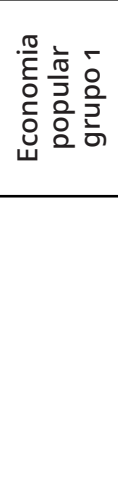 } & $\stackrel{\circ}{\circ}$ & $\underset{m}{\stackrel{v}{m}}$ & $\stackrel{\aleph}{\dot{n}}$ & $\begin{array}{l}0 \\
\dot{f}\end{array}$ & $\begin{array}{l}0 \\
\text { L్ర }\end{array}$ & 号 & $\begin{array}{l}0 \\
\dot{0} \\
\text { in }\end{array}$ & & $\stackrel{\circ}{\infty}$ & 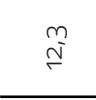 & $\underset{\infty}{+}$ & $\stackrel{m}{\sim}$ & \\
\hline & 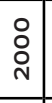 & $\begin{array}{l}0 \\
\stackrel{5}{\sigma}\end{array}$ & $\underset{\mathcal{N}}{\mathcal{F}}$ & 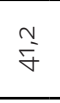 & $\begin{array}{l}\text { đु. } \\
\text { बें }\end{array}$ & 离 & $\stackrel{n}{\stackrel{n}{n}}$ & & $\begin{array}{l}\bar{\infty} \\
\infty\end{array}$ & $\stackrel{\stackrel{2}{\wedge}}{\stackrel{2}{2}}$ & $\stackrel{\infty}{m}$ & $\stackrel{0}{0}$ & \\
\hline & 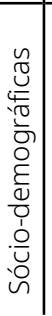 & 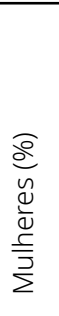 & 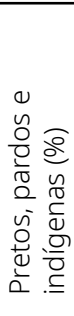 & 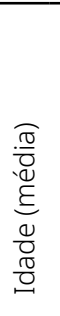 & 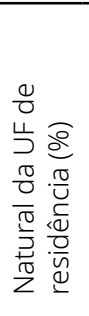 & 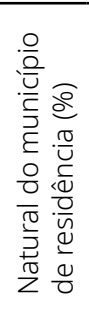 & 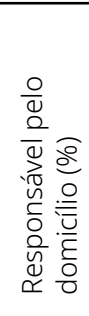 & 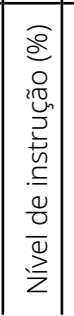 & 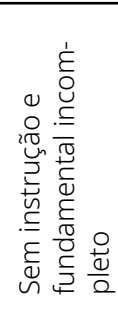 & 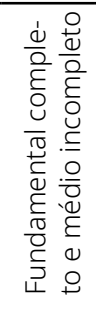 & 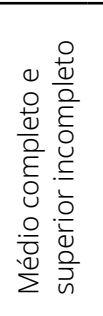 & 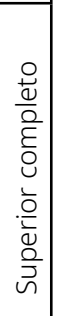 & $\begin{array}{l}\frac{\pi}{\pi} \\
\tilde{\sigma} \\
\dot{N} \\
\frac{\pi}{\alpha}\end{array}$ \\
\hline
\end{tabular}


A economia popular aproxima-se das categorias da economia informal e dos trabalhadores domésticos em termos de escolaridade e cor/etnia, indicando a dicotomia entre um mercado de trabalho formal, que ocupa majoritariamente os trabalhadores brancos e escolarizados, e um informal e popular, que ocupa maior parcela de pretos, pardos e indígenas e de baixa escolaridade. Nota-se, porém, grande avanço nos níveis de escolaridade dos trabalhadores, sobretudo entre, justamente, os grupos da economia popular, domésticos e assalariados sem carteira. Apesar desse movimento favorável, eram esses grupos que apresentavam os menores níveis de escolaridade em 2000 e são os que se mantêm na condição menos favorável.

Em suma, os dados demonstram a relevância e o potencial da economia popular, ao evidenciar o grande número de trabalhadores envolvidos. Essas características permitem que a economia popular e solidária se apresente como estratégia de inserção relevante para públicos específicos, como mulheres e idosos, assim como para as populações tradicionais. Isso é importante mesmo em um contexto de ampliação do emprego formal e de queda significativa do desemprego, como se verificou na década de 2000.

Adicionalmente, as ocupações associadas à economia popular remetem a atividades cuja demanda no período atual é crescente, como é o caso dos serviços pessoais. O mesmo ocorre com relação à produção artesanal, verificada no setor de confecções e alimentação. A demanda crescente pelos produtos e serviços dessas ocupações aparece como oportunidade significativa para a economia popular solidária, juntamente à demanda já consolidada pelos produtos oriundos da agricultura, da pecuária, da pesca e do extrativismo, pelos serviços da construção civil e pelos serviços produtivos (DINIZ, 2019).

\section{Possibilidades para a economia popular e o planejamento metropolitano uma década depois}

A implantação e o fortalecimento de uma economia baseada em pequenos negócios e em novas formas solidárias de organização social e econômica constituem um imenso desafio para o Estado e a sociedade civil organizada, em que pese a importância de ambas as ações como alternativa à exclusão de parcelas significativas da população dos processos centrais da economia capitalista globalizada. A maior parte do aparato institucional e ideológico do Estado está voltada para as grandes e médias empresas capitalistas; trata-se de um quadro consolidado, de difícil reversão, no contexto das políticas públicas, e mesmo na ideologia dominante em quase todos os setores da sociedade, assim como na mídia. A criação da Secretaria Nacional de Economia Solidária, junto ao Ministério do Trabalho e 
do Emprego, atuante de 2003 a 2016 no nível federal, bem como de estruturas nos estados e municípios voltadas para a geração de trabalho e renda no âmbito da pequena produção, sem dúvida significou um avanço expressivo no fortalecimento dessas atividades. Entretanto, os resultados são insuficientes, pois ainda não representam uma alternativa efetiva para a consolidação dos empreendimentos de pequeno porte.

À semelhança do que ocorre em outros espaços no país, a produção em pequena escala em Minas Gerais enfrenta dificuldades de expansão e desenvolvimento, seja na articulação com o circuito superior, seja no provimento de bens e serviços no interior do próprio circuito inferior, vinculadas à necessidade de crédito e assistência técnica, à gestão do empreendimento, à comercialização e à qualidade dos bens e serviços produzidos. Apesar da existência de programas e legislação de apoio a pequenos empreendedores, empresas e grupos produtivos, costumam ser ineficazes no atendimento a esse público, em razão de desconsiderarem peculiaridades que dificultam a integração dos empreendimentos entre si, ao setor público e à produção em larga escala. Tais especificidades passam, por exemplo, pela dificuldade de absorção de tecnologias, pela inadequação aos processos burocráticos e das metodologias dos cursos de formação.

Embora o PDDI-RMBH considere a economia popular e solidária como um dos motores centrais de desenvolvimento, não se consolidaram ações efetivas nesse sentido uma década após sua aprovação. As iniciativas existentes encontram-se pulverizadas entre as secretarias de estado e das prefeituras ${ }^{9}$, sem que se estabeleça um movimento coordenado de apoio e fomento a essa economia.

Após a aprovação do Plano Metropolitano, foi realizado, também pela UFMG, sob supervisão técnica da Agência de Desenvolvimento Metropolitano, o Macrozoneamento da Região Metropolitana de Belo Horizonte (MZ-RMBH). Entendido como uma nova etapa do planejamento da RMBH, orientada pelo PDDI, o MZ buscou identificar áreas de interesse comum da metrópole (Zonas de Interesse Metropolitano, composta de territórios delimitados em que o interesse metropolitano prevalece sobre o local, e Áreas de Interesse Metropolitano, que são porções do território voltadas à implementação de políticas do PDDI) e estabelecer diretrizes para o uso e a ocupação dessas áreas. Essa etapa, finalizada em 2014, contou

\footnotetext{
9. No âmbito estadual, a Secretaria Estadual de Desenvolvimento Social (Sedese) conta hoje com quatro diretorias ligadas à economia solidária, dentro da Superintendência de Políticas de Empreendedorismo e Economia Popular Solidária. Continuam ativos o Conselho Estadual de Economia Popular Solidária, o Fórum Mineiro e o Fórum Metropolitano de Economia Popular Solidária, além de doze fóruns regionais no estado e seis fóruns municipais na RMBH. Diversas prefeituras da RMBH desenvolvem ações voltadas à economia solidária, à agricultura familiar, ao turismo e cultura, entre outras atividades próximas da economia popular.
} 
com o georreferenciamento de empreendimentos econômicos solidários, práticas agrícolas e culturais e equipamentos de referência para a economia popular e solidária. Contou, também, como uma proposta de Trama Verde Azul (TVA), discutida adiante.

Uma terceira etapa do processo de planejamento metropolitano em parceria com a Universidade foi a revisão dos Planos Diretores de onze municípios da RMBH. Nessa fase, o propósito consistia em compatibilizar a gestão do território e a legislação municipal com as diretrizes propostas no PDDI-RMBH e no Macrozoneamento Metropolitano. Tratou-se, ainda, de detalhar as Zonas de Interesse Metropolitano e a Trama Verde Azul segundo as realidades municipais, em busca de maior alinhamento entre o planejamento municipal e o metropolitano. Nessa fase, finalizada em 2018, foi criado em cada um daqueles onze municípios um Grupo de Acompanhamento, com participação paritária do Executivo e do Legislativo municipais e da sociedade civil. Idealmente, esse grupo teria um espaço físico que funcionaria como embrião dos Lugares de Urbanidade Metropolitana (Lumes) ${ }^{10}$.

Os avanços discutidos acima não implicaram, no entanto, uma ação coordenada voltada à economia popular. É nesse sentido que o presente artigo propõe um retorno às propostas e possibilidades apresentadas pelo PDDI-RMBH, com base no entendimento de que são múltiplas as oportunidades não aproveitadas para o desenvolvimento da economia popular e solidária na metrópole. Ao mesmo tempo, é cada vez mais necessário repensar o modelo de desenvolvimento que recai sobre o território, acompanhando as mudanças de orientação de política econômica a cada gestão/mandato nos níveis estadual e municipal (TONUCCI FILHO; FREITAS, 2020)"1

Como caminho possível para a retomada das ideias contidas no PDDI, apontamos para o diálogo existente entre as práticas de economia popular e solidária na metrópole e a proposta de reinterpretação da Trama Verde Azul como Trama Multicolorida, feita por Euclydes (2016). A Trama Verde Azul é um instrumento

10. Os Lumes da RMBH foram concebidos pelo PDDI-RMBH como um dos programas prioritários da Política Metropolitana Integrada de Democratização dos Espaços Públicos: o Programa de Mobilização Social para Implementação do Plano Metropolitano. "Os Lumes são espaços físicos e virtuais de troca de informações e produção de dados locais e também se realizam enquanto processos de ação direta do PDDI voltadas à difusão do conceito de cidadania metropolitana, de modo a servir como uma importante ferramenta de planejamento metropolitano, divulgação de ações metropolitanas afirmativas e um meio de participação da população”. Disponível em: http://www.rmbh.org.br. Acesso em: 8 abr. 2020.

11. A esse respeito, Tonucci Filho e Freitas (2020) discutem os movimentos recentes envolvendo o planejamento metropolitano, o governo estadual e o capital imobiliário, no que diz respeito às novas centralidades metropolitanas. Os autores destacam uma espécie de descompasso entre os grandes projetos urbanos implementados na metrópole e a racionalidade adotada pelo planejamento metropolitano, compreensiva e de longo prazo, assumindo um papel mais ativo do Estado como regulador e como interventor. 
previsto tanto no Plano como no Macrozoneamento metropolitanos. Inicialmente, teve como inspiração a experiência de planejamento na região de Nord-Pas-de-Calais, na França, onde há uma importante bacia carbonífera. A importação desse conceito para o PDDI-RMBH guiou-se pelo intuito de propor um dispositivo de planejamento e engajamento sociopolítico em torno das questões ambientais, sociais e econômicas representadas pelo conjunto da Região Metropolitana. Nesse sentido, a Trama tratava de "espaços de interesse para a articulação das políticas de recursos hídricos e de áreas protegidas e áreas verdes, com destaque para os parques lineares”, relacionados à mobilidade urbana, mas conjugados com as problemáticas da integração econômica regional e com as disparidades sociais (EUCLYDES, 2016, p. 163).

A Trama, considerada um instrumento de planejamento, e tendo em vista seus objetivos e áreas priorizadas, evidencia que não se reduz a uma forma de planejamento centrada na natureza - portanto, ela excede a experiência francesa, ao incorporar elementos dotados de centralidade para a vida cotidiana metropolitana. O conceito de trama utópica (EUCLYDES, 2016) nos permite compreendê-la como uma proposta de planejamento alternativo da RMBH: pensada dentro dessa conceituação, a Trama "consistiria no esboço de um projeto de uma transformação socioespacial, fundado na natureza e nos temas e usos de menor interesse do capital - como a vida cotidiana, a produção em pequena escala e a economia solidária” (EUCLYDES, 2016, p. 169-170). Para a autora, a trama poderia ser concebida como algo além de um plano estatal de planejamento territorial, "mas como uma expressão da transformação da vida cotidiana”. Nessa perspectiva, ela comportaria um aspecto de expansão-reunião:

A expansão, por um lado, expressa a difusão da trama em rede por todo o espaço, física e virtualmente, unindo experiências vizinhas e distantes e estendendo a Festa, a comunalização, a agroecologia urbana e a economia solidária ao espaço como um todo. A reunião, por outro lado, engendra a integração daquilo que a era industrial deixou em fragmentos - sejam os espaços de vida, que se moldam à escala do corpo, pressupõem a simultaneidade, transcendem as especializações funcionais (como as inerentes às áreas verdes e áreas protegidas) e ensejam encontros, sejam as atividades cotidianas, que passam a não discernir claramente produção de consumo, trabalho de não trabalho, cotidiano de não cotidiano, atividade intelectual de atividade manual, necessidade de desejo, valor de troca de valor de uso, natureza humana de natureza não humana (EUCLYDES, 2016, p. 229). 
Nesse sentido, a economia popular e solidária, como um conjunto de práticas de caráter solidário que se orienta para a transição da economia do capital para a economia do trabalho (CORAGGIO, 2003, 2013), poderia ser pensada simultaneamente como resultado desse processo de expansão e como possível horizonte de trabalho. A Política Metropolitana Integrada de Apoio à Produção em Pequena Escala (UFMG, 2011) permite vislumbrar uma série de concatenações possíveis entre as políticas previstas, as atividades e iniciativas já desenvolvidas no território metropolitano e a Trama Verde Azul, ressignificada como Trama Multicolorida. É possível, ainda, considerar uma articulação com os Lumes, em face de sua potência de reunião de iniciativas econômicas e culturais, como grupos produtivos, coletivos de jovens, coletivos culturais, entre outros ${ }^{12}$.

Dentro da referida Política, encontram-se alguns programas particularmente interessantes no que se refere a essa integração, como é o caso do Programa de Elevação da Qualidade e da Competividade da Pequena Produção, que prevê a criação de espaços de apoio e divulgação das experiências locais, a fim de ampliar o acesso ao microcrédito produtivo e a novas concepções metodológicas e estabelecer a conexão entre escolas técnicas, ONGs, instituições de ensino superior, bancos comunitários, etc. (UFMG, 2011). A elevação da competividade da pequena produção é de extrema importância no contexto metropolitano no tocante à viabilização da disputa econômica e sociopolítica diante do grande capital e dos grandes investimentos de caráter predatório.

No Programa de Apoio à Regulamentação e Instalação de Empreendimentos Individuais, Empreendimentos Solidários, Microempresas e Empresas de Pequeno Porte (UFMG, 2011), também chamam atenção alguns projetos específicos, com potencial de integração à Trama Verde Azul. Esse é o caso do Projeto de Fomento a Pequenos Arranjos Produtivos de Turismo de Base Comunitária, com incentivos a restaurantes e empreendimentos familiares associados; redes de artesanato e lugares de socialização da produção (feiras, mercados, festas, etc.); redes de hospedagem familiares; entre outros.

O PDDI-RMBH prevê igualmente, dentro da Política Metropolitana Integrada de Apoio à Produção em Pequena Escala, o Programa de Criação de uma Rede Metropolitana de Produção e Consumo Solidário (UFMG, 2011), com uma gama de projetos voltados para o estabelecimento de feiras periódicas e permanentes ao longo do território da RMBH, pontos fixos de comercialização pautados pela

12. Como um dos desdobramos do processo de planejamento metropolitano em parceria com a UFMG, vem sendo ofertada regularmente a estudantes de graduação a disciplina de formação em extensão universitária Lumes. Nessa disciplina, os estudantes têm contato com os Lumes já constituídos e promovem ações culturais, de debate e de formação em torno do planejamento metropolitano. 
economia popular e solidária e pela agroecologia. Além disso, propõe o incentivo ao consumo solidário por meio do estabelecimento de redes e cadeias produtivas locais e solidárias, capazes de articular produtores e consumidores dentro de outra lógica de produção e circulação dos produtos.

Todos os exemplos apresentados podem ser concebidos como resultado de uma articulação mais ampla com as propostas previstas na Trama Verde Azul. A ideia de uma rede articulada em torno da questão ambiental e ampliada pelas potencialidades econômicas alternativas e emancipatórias locais confere à economia popular e solidária maior capacidade de se estabelecer como alternativa viável de desenvolvimento endógeno, regional e territorial.

\section{Considerações finais}

Este artigo buscou aproximar as ideias de economia popular e solidária e de desenvolvimento endógeno, fundamentando-se no caso do PDDI-RMBH. Propôs-se, ainda, discutir os limites e as potencialidades concretas para a economia popular tornar-se base desencadeadora de uma trajetória de desenvolvimento endógeno, uma década após a elaboração e a aprovação do Plano Diretor.

Para tanto, na primeira seção discutiu-se o desenvolvimento endógeno como paradigma possível e suas relações com a economia popular, a economia solidária e o desenvolvimento solidário. Em seguida, tratou-se da inserção da ideia de economia popular e solidária nas propostas do PDDI-RMBH. Na terceira seção, comentam-se o PDDI-RMBH e a proposta de uma "novíssima economia mineira". A quarta seção apresentou uma análise descritiva da economia popular em Minas Gerais por meio de uma adaptação de categorias dos censos demográficos 2000 e 2010 (IBGE). Com base nessas reflexões, na quinta seção discutem-se as possibilidades atuais para a economia popular, revisitando algumas propostas do Plano ainda não implementadas.

Embora o PDDI-RMBH destaque as práticas da economia popular e solidária como parte significativa da economia metropolitana e as identifique como eixo central do desenvolvimento econômico na metrópole, pode-se dizer que a condução das políticas de planejamento, ao longo da última década, não considerou, de fato, a economia popular (solidária) como um dos motores centrais de desenvolvimento. As iniciativas de fomento a essa produção se encontram pulverizadas entre as secretarias de estado e das prefeituras, sem consolidar um movimento coordenado. É nesse sentido que o presente artigo propõe um retorno às propostas e possibilidades apresentadas pelo Plano, as quais avançaram nas fases posteriores do planejamento metropolitano, mas não se materializaram como ações no território. 
Abordou-se na quinta seção a existência, na RMBH, de uma gama de atores e práticas econômicas que poderiam ser reunidos no instrumento da Trama Verde Azul, capaz de articular essa proposta como transformação da vida cotidiana (EUCLYDES, 2016; OLIVEIRA; COSTA, 2018). Nesse sentido, devem-se ter em vista o fortalecimento de tais atividades, por meio de ações de visibilização, consolidação e apoio, e a construção de redes de empreendimentos que incorporem a diversidade territorial e a cultural: empreendimentos ligados aos fóruns mineiro, municipais e metropolitano de economia solidária, sobretudo aqueles ligados às redes de artesanato, reciclagem, produtos de higiene e limpeza e confecções; experiências de agricultura urbana, agroecologia urbana e agricultura familiar; experiências de autoconstrução; experiências de turismo de base comunitária e turismo familiar, englobando possíveis redes de restaurantes familiares, produção artesanal de alimentos, ecoturismo, turismo ecológico e turismo rural; coletivos de arte e cultura, em sua articulação com centros culturais comunitários e outros equipamentos culturais; cooperativas de prestação de serviços, como alimentação, transportes e serviços de cuidado; bancos comunitários e suas experiências de moedas sociais.

Um primeiro esforço necessário seria integrar ações e programas institucionais já existentes, levando-se em consideração os diversos níveis de organização produtiva dos empreendimentos e suas inserções territoriais, com vistas a estabelecer uma rede de articulação permanente entre os empreendimentos, as organizações governamentais e as entidades de fomento. Essa rede seria a base para o fortalecimento e a organização dos empreendimentos por meio da elaboração de metodologias específicas de apoio e fomento; da ampliação de compras públicas da produção; da ampliação de espaços de comercialização; da criação de redes de fornecedores locais e de redes de consumo solidário; da adequação das linhas de microcrédito produtivo orientado; entre outras ações propostas no Plano.

Desse modo, entendemos o PDDI-RMBH como um instrumento de planejamento que identifica na economia popular metropolitana e nos seus mais diversos encadeamentos territoriais a possibilidade de dar início a um processo de redirecionamento da economia mineira no sentido do desenvolvimento endógeno. Tal desenvolvimento poderia ser compreendido nos termos apresentados por Paul Singer (2004) para o desenvolvimento solidário - isto é, um processo de instauração de novas relações de produção que busquem promover o crescimento econômico de maneira sustentável, aliado à preservação da natureza e à redistribuição social dos frutos desse crescimento. 


\section{Referências}

CORAGGIO, J. L. Economía urbana: la perspectiva popular. Quito: Instituto Fronesis, 1994.

Da economia dos setores populares à economia do trabalho. In: KRAYCHETE, G. et al. (org.). Economia dos setores populares: entre a realidade e a utopia. Petrópolis: Vozes, 2000.

Qué significa pasar de la economía popular a la economía del trabajo? Proposta, n. 98, p. 12-20, 2003.

Las tres corrientes de pensamiento y acción dentro del campo de la economía social y solidaria. Revista Brasileira de Estudos Urbanos e Regionais, v. 15, n. 2, p. 11-24, 2013.

DAGNINO, R. Tecnologia social: contribuições conceituais e metodológicas. Campina Grande: EDUEPB, 2014.

DINIZ, C. C. Estado e capital estrangeiro na industrialização mineira. Belo Horizonte: UFMG/ Proed, 1981.

DINIZ, C. C.; CROCCO, M. Economia regional e urbana: contribuições teóricas recentes. Belo Horizonte: Editora UFMG, 2006.

DINIZ, S. C. Do precário ao plural: realidades e possibilidades da economia popular no Brasil contemporâneo. 2016. Tese (Doutorado) - Centro de Desenvolvimento e Planejamento Regional da Faculdade de Ciências Econômicas da Universidade Federal de Minas Gerais, Belo Horizonte, 2016.

Economia popular e solidária no Brasil contemporâneo. In: ANDRADE, M. V.; ALBUQUERQUE, E. M. (org.). Alternativas para uma crise de múltiplas dimensões. Belo Horizonte, Cedeplar/UFMG, 2018.

. Possibilidades da economia popular e solidária no Brasil contemporâneo: apontamentos. Nova Economia, v. 29, p. 963-985, 2019.

DINIZ, S. C.; MONTE-MÓR, R. L. M. A pequena produção popular e solidária como instrumento de fortalecimento e reorganização metropolitana: a visão do PDDI-RMBH. In: Anais do XV Encontro da Anpur - Enanpur, Recife, 2013.

DINIZ, S. C.; ROCHA, V. M. Panorama da economia solidária no estado de Minas Gerais. Boletim Mercado de Trabalho - Conjuntura e Análise, v. 66, p. 1-12, 2019.

EUCLYDES, A. C. P. A hipótese otimista: dialética e utopia das áreas verdes, das áreas protegidas e da Trama Verde e Azul. 2016. Tese (Doutorado) - Escola de Arquitetura da Universidade Federal de Minas Gerais, Belo Horizonte, 2016.

FURTADO, C. Criatividade e dependência na civilização industrial. São Paulo: Paz e Terra, 1978. Cultura e desenvolvimento em época de crise. Rio de Janeiro: Paz e Terra, 1984.

HIRATA, G. I.; MACHADO, A. F. Conceito de informalidade/formalidade e uma proposta de tipologia. Boletim Mercado de Trabalho - Conjuntura e Análise, n. 34, nov. 2007. 
INSTITUTO BRASILEIRO DE GEOGRAFIA E ESTATÍSTICA (IBGE). Censo Demográfico, 2000. Disponível em: http://www.ibge.gov.br. Acesso em: 8 abr. 2020.

. Censo Demográfico, 2010. Disponível em: http://www.ibge.gov.br. Acesso em: 8 abr. 2020.

KRAYCHETE, G. Economia popular solidária: paisagens e miragens. Serviço Social em Revista (on-line), v. 9, n. 1, p. 1-15, 2006.

LISBOA, A. M. Socioeconomia solidaria: marco conceitual latinoamericano. Textos para discussão UFSC CNM, n. 2, 2004.

MONTE MÓR, R. L. M. Urbanização extensiva e economia dos setores populares. In: OLIVEIRA, M. P. et al. (org.). O Brasil, a América Latina e o mundo: espacialidades contemporâneas. Rio de Janeiro: Lamparina/Faperj/Anpege, 2008.

MONTE-MÓR, R. L. M.; COSTA, G. M.; COSTA, H. S. M.; MELO, M. G. P. The University and Metropolitan Planning: an Innovative Experience. Nova Economia, v. 26, p. 1133-1156, 2016.

MONTE-MÓR, R. L. M.; DINIZ, S. C. Economias populares: alternativas de geração de trabalho e renda na Região Metropolitana de Belo Horizonte. In: OLIVEIRA, F. L. de et al. (org.). Grandes projetos metropolitanos: Rio de Janeiro e Belo Horizonte. Rio de Janeiro: Letra Capital, 2012.

OLIVEIRA, A. M.; COSTA, H. S. M. A Trama Verde Azul no planejamento territorial: aproximações e distanciamentos. Revista Brasileira de Estudos Urbanos e Regionais, v. 20, n. 3, p. 538-555, 2018.

OLIVEIRA. F. A razão dualista/O ornitorrinco. São Paulo: Boitempo, 2003 [1972].

RAZETO, L. De la economía popular a la economía de solidaridad en un proyecto de desarrollo alternativo. Ciudad de México: Instituto Mexicano de Doctrina Social Cristiana, 1993.

RODRÍGUEZ, O. O estruturalismo latino-americano. Rio de Janeiro: Civilização Brasileira, 2009 [2006].

SANTOS, M. O espaço dividido: os dois circuitos da economia urbana dos países subdesenvolvidos. São Paulo: Edusp, 2008 [1979].

SINGER, P. I. Introdução à economia solidária. São Paulo: Editora Fundação Perseu Abramo, 2002.

. Desenvolvimento capitalista e desenvolvimento solidário. Estudos Avançados, v. 18, n. 51, p. 7-22, 2004.

TIRIBA, L. O trabalho no olho da rua: fronteiras da economia popular e da economia informal. Proposta, n. 97, p. 38-49, jun.-ago. 2003.

TONUCCI FILHO, J. B. M. Dois momentos do planejamento metropolitano em Belo Horizonte: um estudo das experiências do Plambel e do PDDI-RMBH. 2012. Dissertação (Mestrado) - Faculdade de Arquitetura e Urbanismo, Universidade de São Paulo, São Paulo, 2012.

TONUCCI FILHO, J. B. M.; FREITAS, D. M. Planejamento metropolitano e grandes projetos urbanos: concepção e descaminhos da política de novas centralidades na RMBH. Cadernos Metrópole, 22(47), p. 61-84, 2020. 
TONUCCI FILHO, J. B. M.; MONTE MÓR, R. L. M. Avanços e desafios ao planejamento metropolitano: o caso do PDDI-RMBH. In: Anais do XV Encontro da Anpur - Enanpur, Recife, 2013.

UNIVERSIDADE FEDERAL DE MINAS GERAIS (UFMG). Plano Diretor de Desenvolvimento Integrado da Região Metropolitana de Belo Horizonte (PDDI-RMBH). Relatório final - propostas de políticas setoriais, projetos e investimentos prioritários. 6 v. Belo Horizonte: UFMG, 2011. Disponível em: http://www.rmbh.org.br. Acesso em: 8 abr. 2020.

VELLOSO, R. C. L.; WOJCIECHOWSKI, M. J. Processos participativos no planejamento da RMBH: perspectivas e desafios na elaboração do Plano Diretor de Desenvolvimento Integrado da Região Metropolitana de Belo Horizonte (PDDI-RMBH). In: ANDRADE, L. T. de; MENDONÇA, J. G. de; DINIZ, A. M. (org.). Belo Horizonte: transformações na ordem urbana. Rio de Janeiro: Carta Capital/PUC Minas, 2015. 


\section{Evandro Luis Alves}

Graduado em Ciências Econômicas pela Faculdade de Ciências Econômicas da UFMG, mestrando em Arquitetura e Urbanismo na Escola de Arquitetura da UFMG (NPGAU-EA/ UFMG) e pesquisador associado do Núcleo RMBH do programa INCT Observatório das Metrópoles.

Email: evandroluisalves13@gmail.com

ORCID: 0000-0003-2156-7527

Contribuição de autoria: conceituação; investigação/pesquisa; metodologia; escrita - primeira redação.

\section{Bruno Siqueira Fernandes}

Graduado em Ciências Econômicas pela Faculdade de Ciências Econômicas da UFMG, mestrando em Geografia no Instituto de Geociências da UFMG (IGC/UFMG).

Email: brunoggsiqueira@gmail.com

ORCID: 0000-0002-5614-4834

Contribuição de autoria: conceituação; investigação/pesquisa; metodologia; escrita - primeira redação; escrita - revisão e edição.

\section{Sibelle Cornélio Diniz}

Doutora em Economia pelo Centro de Desenvolvimento e Planejamento Regional da Faculdade de Ciências Econômicas da UFMG (Cedeplar-Face/UFMG), professora adjunta do Departamento de Ciências Econômicas e do Cedeplar/UFMG.

Email: sibelle.diniz@gmail.com

ORCID: 0000-0002-3183-3588

Contribuição de autoria: conceituação; curadoria de dados; análise formal; investigação/pesquisa; metodologia; escrita - primeira redação; escrita - revisão e edição.

Submissão: 17 de setembro de 2019.

Aprovação: 5 de maio de 2020 .

Como citar: ALVES, E. L.; FERNANDES, B. S.; DINIZ, S. C. O PDDI-RMBH e as possibilidades de um desenvolvimento endógeno desencadeado pela economia popular metropolitana. Revista brasileira de estudos urbanos e regionais. v. 22, E202016, 2020. DOI 10.22296/2317-1529.rbeur.202016

Artigo licenciado sob Licença Creative Commons CC BY-NC 4.0. https://creativecommons.org/licenses/by-nc/4.o/deed.pt_BR 